\title{
HYDRAULIC TRANSIENT EXPERIMENTAL STUDY IN A COPPER PIPE
}

\author{
PIERFABRIZIO PUNTORIERI ${ }^{1}$, GIUSEPPE BARBARO ${ }^{1}$, NUNO M. C. MARTINS ${ }^{2}$, \\ DÍDIA COVAS ${ }^{2} \&$ VINCENZO FIAMMA $^{2}$ \\ ${ }^{1}$ Mediterranea University, Italy \\ ${ }^{2}$ CERIS, Universidade de Lisboa, Portugal
}

\begin{abstract}
Water hammer is generated when a change of the flow occurs, causing fluid particles to rapidly accelerate and to decelerate. This paper presents the results of measurements carried out in an experimental laboratory pipe-rig, confirming that the classic water hammer theory does not apply in the presence of cavitating flow. The research also shows the steady and dynamic behaviour of the system due to the valve closure.

Keywords: hydraulic transients, water hammer, cavitation, check valve, copper pipe systems.
\end{abstract}

\section{INTRODUCTION}

The water hammer has always been an area of study, which has captivated the minds of researchers due to its complex and challenging phenomena. It has been known to cause serious ruptures and losses in pipe systems. For these reasons, there are extensive studies on literature related to water hammer, for example, Shamloo and Mousavifard [1], Libraga et al. [2] and Bruce and David [3]. The water hammer is a phenomenon generated when there is a change in the flow regime, in a pressurised pipe, causing the acceleration and deceleration of particles in the flow inside the pipe system. This paper presents the results of measurements carried out in the laboratory pipe-rig, confirming that the classic water hammer theory is not always valid in the presence of the cavitation. Three initial discharges are analysed with different closure positions, in steady state conditions. To improve the results of the numerical modelling, the valve manoeuvres need to be adjusted to fit the experimental data. This research analyses the behaviour of the system, in steady state flow, for different positions of the valve closure and compares collected data for different transient events. The aim of the research is to show the steady and dynamic behaviour of the system due to the valve closure.

\section{EXPERIMENTAL FACILITY}

This section presents a description of the experimental system and of the experimental programme carried out in a pipe-rig, assembled in the Laboratory of Hydraulics and Environment at the Department of Civil Engineering, Architecture and Georesources, in the Instituto Superior Técnico, Lisbon, Portugal.

The pipe system comprises a $15.22 \mathrm{~m}$ of copper pipe with an internal diameter of 20 $\mathrm{mm}$ and a wall thickness of $1 \mathrm{~mm}$. Fig. 1 presents the schematic of the pipe rig. The system operates at an approximately constant piezometric head, maintained by a pump with a nominal flow rate of $\mathrm{Q}=55 \mathrm{l} / \mathrm{min}$ at the upstream end, followed by a $60 \mathrm{~L}$ hydropneumatic vessel. At the downstream end, a valve setup is positioned: first a pneumatic actuated spherical valve, the one that generates the water hammer, followed by a manually controlled spherical valve to control the flow rate, which is measured by a rotameter positioned after the valves setup. After the rotameter, the flow goes through a plastic pipe to a free surface storage tank that continuously supplies the system pump. Two pressure transducers are installed in the system: at the upstream of the pneumatic valve (PT1), and at the pipe 
mid-section (PT2). The pressure transducers (WIKA S-10) have a nominal pressure of 25 bars and a span of $0.5 \%$.

The data acquisition signal converts all signals into numerical data by the digital oscilloscope (PicoScope ${ }^{\mathrm{TM}}$ ). The oscilloscope is then connected to a computer to storage.

\section{TRANSIENT DATA COLLECTION}

The instrumentation used for the measurement of the piezometric head time variation of composed of: two pressure transducers, an oscilloscope (Picoscope 3424) and a laptop computer. Seventeen tests have been carried out for different initial discharges and, for each

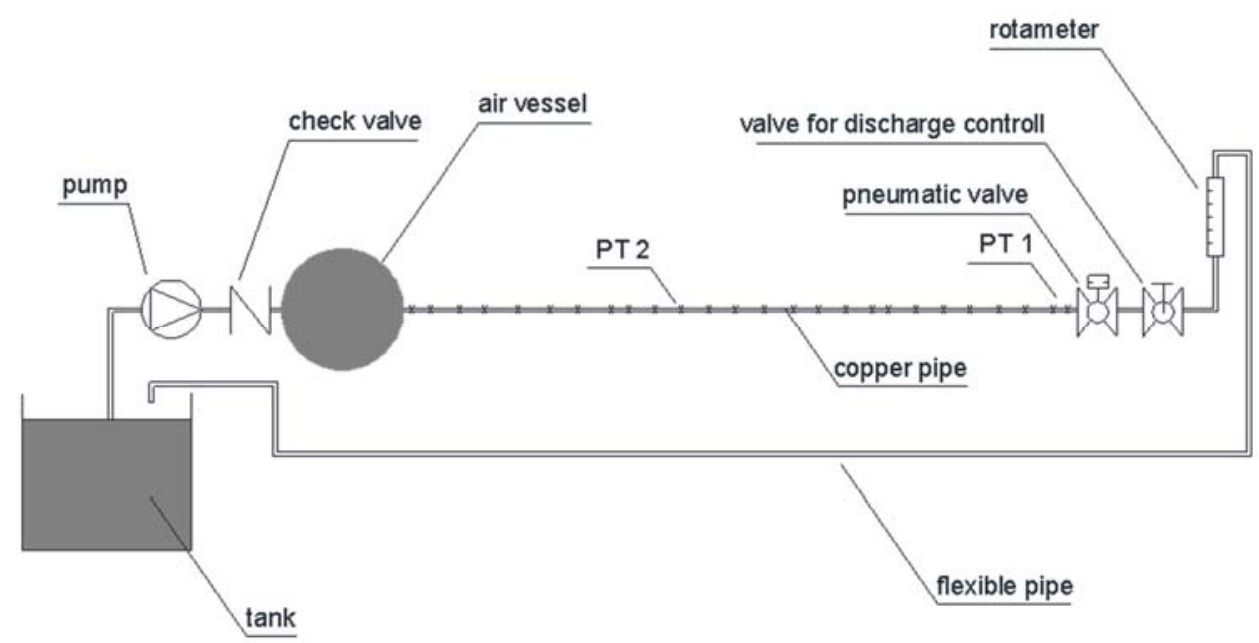

Figure 1: Schematic of the copper pipe system.

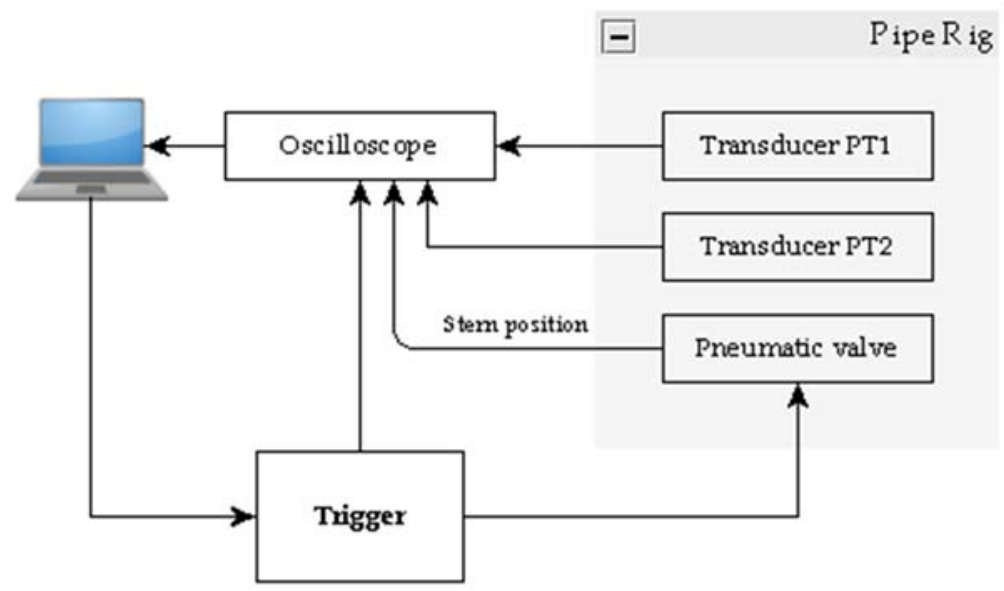

Figure 2: Scheme of the data acquisition system. 
discharge, the tests were repeated 20 times for obtaining the time-averaging. The water hammer was generated by instantaneous closure of the downstream end valve. Table 1 presents data obtained from the transient tests, namely the discharges and the corresponding maximum, minimum and amplitude of variation of the piezometric head, $\Delta \mathrm{H}_{\exp }$ (which is the difference between the maximum piezometric head and the steady state one). Two values of celerity, the theoretical and the experimental, are also presented. The relative error between observed and theoretical Joukowsky overpressure, $\Delta \mathrm{H}_{\mathrm{J}}$, are also presented.

The celerity was measured experimentally as:

$$
c_{\exp }=\frac{4 L}{T}
$$

Joukowsky overpressure is calculated using eqn (2):

$$
\Delta H_{\text {Joukowsky }}=\frac{c_{\text {exp }} \Delta v}{g}
$$

where $\mathrm{T}=$ the wave period, $\mathrm{L}=$ the pipe length, $\mathrm{g}=$ the gravitational acceleration, $\Delta v=$ the mean velocity variation. In conclusion it is estimated that, the relative error in which it was

Table 1: Table list of tests.

\begin{tabular}{|l|l|l|l|l|l|l|l|l|}
\hline Q & $\begin{array}{l}\text { Hsteady } \\
\text { state }\end{array}$ & Hmax & Hmin & $\Delta \mathrm{H}_{\exp }$ & $\begin{array}{l}\text { Celerity } \\
\text { theor. }\end{array}$ & $\begin{array}{l}\text { Celerity } \\
\text { exp. }\end{array}$ & $\begin{array}{l}\text { Joukowsky } \\
\text { overpressure, } \\
\Delta \mathrm{H}_{\mathrm{J}}\end{array}$ & $\begin{array}{l}\text { Relative } \\
\text { Error }\end{array}$ \\
\hline$[\mathrm{L} / \mathrm{h}]$ & {$[\mathrm{m}]$} & {$[\mathrm{m}]$} & {$[\mathrm{m}]$} & {$[\mathrm{m}]$} & {$[\mathrm{m} / \mathrm{s}]$} & {$[\mathrm{m} / \mathrm{s}]$} & {$[\mathrm{m}]$} & {$[\%]$} \\
\hline 115 & 47.03 & 61.31 & 32.11 & 14.28 & 1270 & 1242.45 & 12.89 & $9.7 \%$ \\
\hline 155 & 46.95 & 65.70 & 27.28 & 18.74 & 1270 & 1255.26 & 17.55 & $6.3 \%$ \\
\hline 192.6 & $\mathbf{4 6 . 0 2}$ & $\mathbf{6 8 . 6 6}$ & $\mathbf{2 1 . 9 2}$ & $\mathbf{2 2 . 6 4}$ & $\mathbf{1 2 7 0}$ & $\mathbf{1 2 5 5 . 2 6}$ & $\mathbf{2 1 . 8 1}$ & $\mathbf{3 . 6 \%}$ \\
\hline 235.6 & 46.74 & 74.67 & 17.58 & 27.93 & 1270 & 1255.26 & 26.68 & $4.5 \%$ \\
\hline 281.2 & 46.56 & 80.26 & 11.44 & 33.70 & 1270 & 1255.26 & 31.85 & $5.5 \%$ \\
\hline 314.9 & 46.44 & 84.90 & 6.72 & 38.46 & 1270 & 1255.26 & 35.67 & $7.3 \%$ \\
\hline 354.7 & 46.27 & 89.62 & 1.19 & 43.35 & 1270 & 1255.26 & 40.18 & $7.3 \%$ \\
\hline 406.1 & 46.01 & 94.61 & -4.05 & 48.60 & 1270 & 1255.26 & 45.99 & $5.4 \%$ \\
\hline 450.6 & 45.94 & 99.24 & -7.62 & 53.30 & 1270 & 1255.26 & 51.03 & $4.3 \%$ \\
\hline 491.8 & 45.57 & 102.60 & -9.27 & 57.03 & 1270 & 1255.26 & 55.70 & $2.3 \%$ \\
\hline 523.1 & 45.70 & 135.44 & -9.97 & 89.74 & 1270 & 1255.26 & 59.24 & $34.0 \%$ \\
\hline 574.2 & 46.17 & 152.52 & -10.07 & 106.35 & 1270 & 1255.26 & 65.03 & $38.9 \%$ \\
\hline 614.3 & 46.29 & 174.60 & -10.21 & 128.31 & 1270 & 1255.26 & 69.57 & $45.8 \%$ \\
\hline 614.3 & 46.47 & 174.68 & -10.26 & 128.21 & 1270 & 1255.26 & 26.68 & $79.2 \%$ \\
\hline 709.6 & 47.00 & 172.51 & -10.21 & 125.51 & 1270 & 1255.26 & 80.37 & $36.0 \%$ \\
\hline 752.8 & 47.48 & 167.84 & -10.29 & 120.35 & 1270 & 1035.05 & 70.30 & $41.6 \%$ \\
\hline 801.7 & 47.65 & 160.17 & -10.19 & 112.52 & 1270 & 1014.67 & 73.39 & $34.8 \%$ \\
\hline & & & & & & & & \\
\hline
\end{tabular}


found by using the following eqn (3):

$$
R E=\frac{\left(H_{\text {max }}-H_{\text {steady }}\right)-\Delta H_{\text {Joukowsky }}}{H_{\text {max }}-H_{\text {steady }}}
$$

Two cases are chosen to illustrate the phenomenon of the water hammer with and without cavitation: tests with discharges of $192.6 \mathrm{~L} / \mathrm{h}$ and of $709.6 \mathrm{~L} / \mathrm{h}$. These tests were chosen to represent two different situations: a transient test without cavitation and a test with cavitation. In the first case (Fig. 3), it can be seen that at time $t=0.2 \mathrm{~s}$, the maximum values of the two pressure signals collected at two different locations (PT1 and PT2) are almost overlapped while in the second test (Fig. 4), two additional pressure peaks appear in the transient phase [12]. As mentioned previously, this is due to the phenomenon of cavitation. For this setup, cavitation occurs for initial steady-state discharges higher than $523.1 \mathrm{~L} / \mathrm{h}$; after this value, the R.E. increases. This confirms that the classic water hammer theory is not always valid in the presence of cavitation [5]-[10].

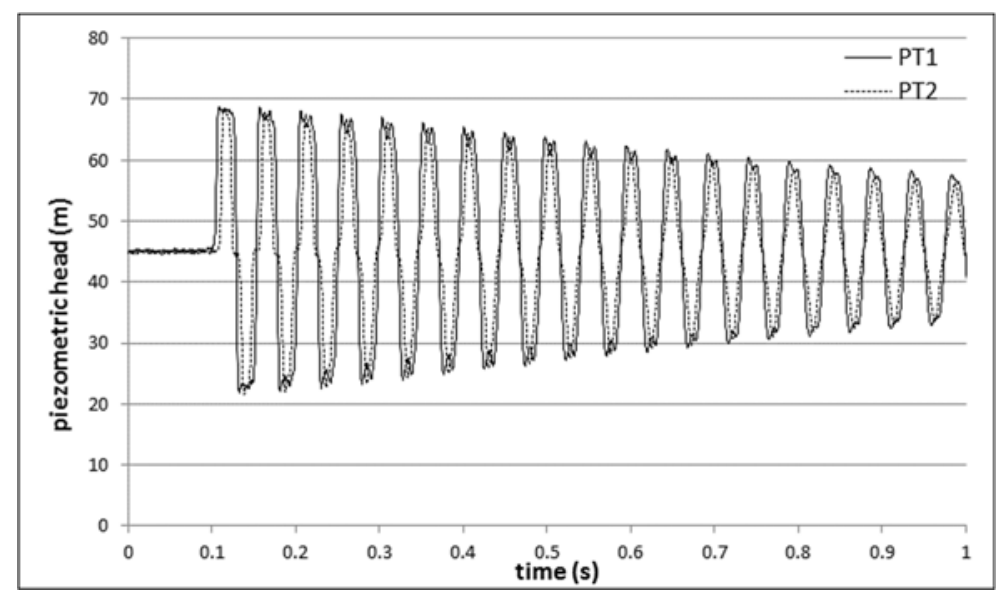

Figure 3: Time history of the piezometric head for $\mathrm{Q}_{0}=192.6 \mathrm{~L} / \mathrm{h}$.

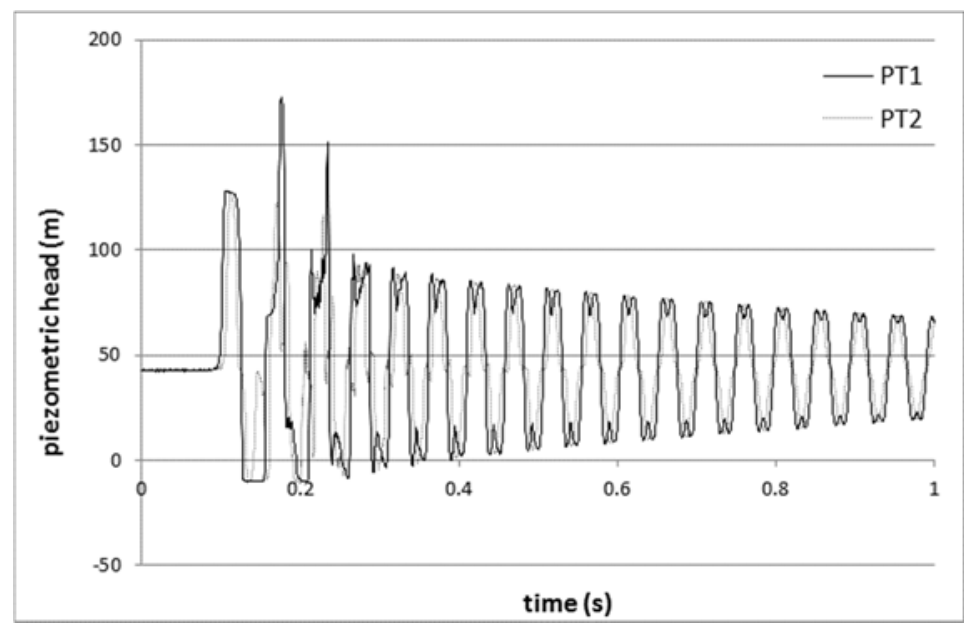

Figure 4: Time history of the piezometric head for $\mathrm{Q}_{0}=709.6 \mathrm{~L} / \mathrm{h}$. 


\section{VALVE DATA COLLECTION}

Valves play a fundamental role in the control of the flow within the pipe systems. In this research, two valves are used: one to control the flow and the other one to generate the water hammer. Two factors can influence the way how pressure variates during the closure of a valve: the type of valve and the rate of closure. The experimental tests were carried out to measure the flow rate variation with the percentage of the closure of the control valve (spherical valve) [13]. As a manual valve was used, the minimum value of the approximate extent shown by the rotameter is $40 \mathrm{~L} / \mathrm{h}$. The whole experiment was repeated three times (in three different conditions), in which a second valve at the beginning of each experiment was allowed to control the flow rate and set it to three maximum values. The first test was carried out with a discharge of $439.3 \mathrm{~L} / \mathrm{h}$, the second test $358.9 \mathrm{~L} / \mathrm{h}$ and the last test $290.5 \mathrm{~L} / \mathrm{h}$. The results are shown in Fig. 5.

The tests start from a fully opened valve. Subsequently, the valve is manually closed, and the position of the valve is video recorded. The test is repeated for two other maximum initial flow rates. Fig. 6 presents the different phases of the valve closure (i.e., between $0^{\circ}$ up to $80^{\circ}$ ). The behaviour of the flow remains almost constant in all three cases for a degree of closure higher than $55^{\circ}$.

After this threshold, through minor movements of the valve, the flow drastically decreases to zero, agreeing with the data available in the literature [8]. This shows that the interaction that arises between the valves and the flow in a pipe system is complex and not linear, [6]-[8].

\section{CONCLUSION}

The results carried out in the laboratory confirmed that the classic water hammer theory is not always valid, [7]-[9]. The sudden transient pressure drops and, subsequently, the transient cavitation occurs only for flow rates higher than $523.1 \mathrm{~L} / \mathrm{h}$; this phenomenon is increasingly evident with the increasing of the initial flow rate. The section 4 shows that the interaction which arises between the valves and the flow in a pipe system is complex and not linear since the behaviour of the flow remains almost constant in all three cases for a degree of closure higher than $55^{\circ}$. After this threshold, through minor movements of the valve, the flow drastically decreases to zero. Engineers should be aware of this risk and should make

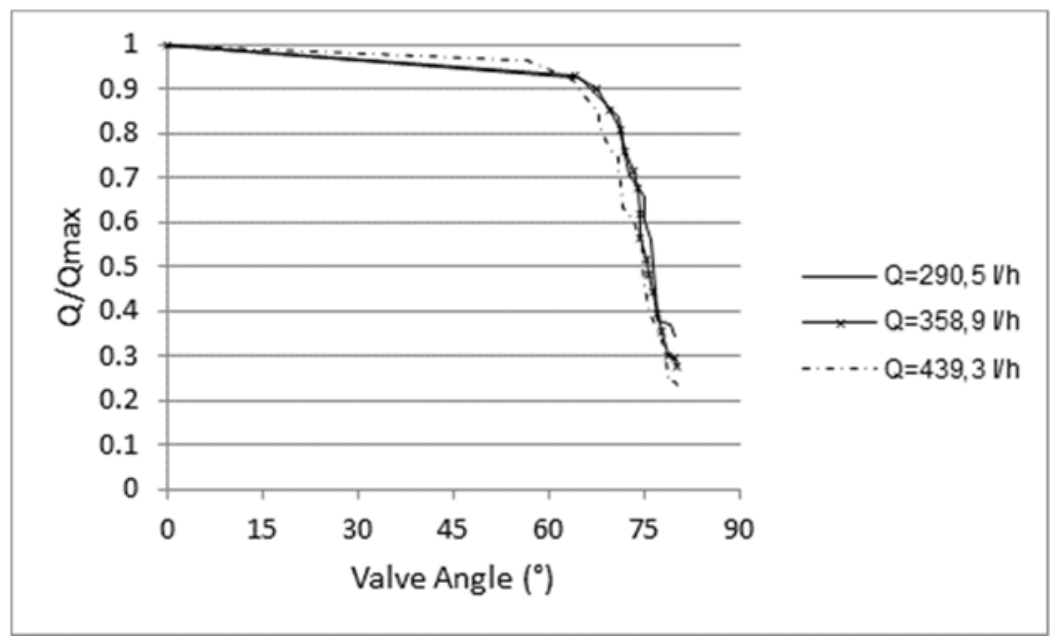

Figure 5: Tests for valve closure time, dimensionless flow rate vs. closure angle. 


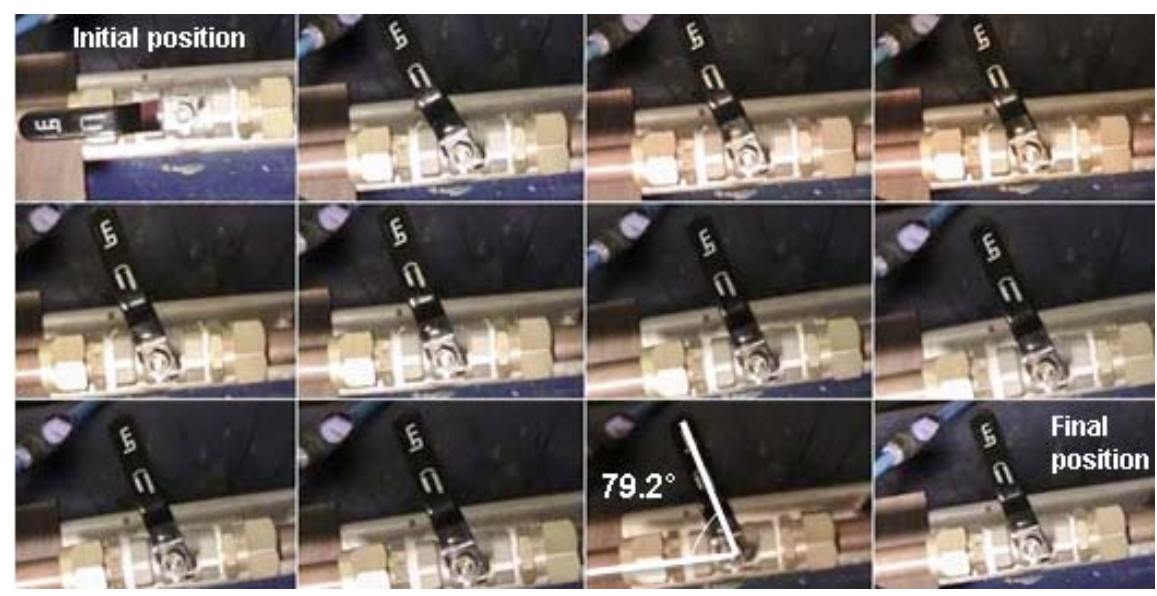

Figure 6: Rotating valve from $358.9 \mathrm{~L} / \mathrm{h}$ to $40 \mathrm{~L} / \mathrm{h}$.

proper use of modern techniques and software to ensure that these water hammer problems are dealt with adequately.

\section{ACKNOWLEDGEMENT}

This work was supported by the Laboratory of Hydraulics and Environment (LHE) of Instituto Superior Técnico (IST).

\section{REFERENCES}

[1] Shamloo, H. \& Mousavifard, M., Numerical Simulation of Turbulent Pipe Flow for Water Hammer. ASME J. of Fluids Eng, 137(11), 2015.

[2] Libraga, J., Ribeiro, R., Covas, D. \& Ramos, H., Experimental and Numerical Analysis of Water Hammer in a Metal Pipe Rig. 11th International Conference on Computing and Control for the Water Industry, Exeter, UK, 2011.

[3] Bruce, S. \& David, S., Water Hammer: Practical Solutions, Butterworth-Heinemann, London, 1995.

[4] Apollonio, C., Covas, D., De Marinis, G., Leopardi, A. \& Ramos, H., Creep Functions for Transients in HDPE Pipes. Urban Water Journal, 2013.

[5] Soares, A., Martins, N. \& Covas, D., Investigation of Transient Vaporous Cavitation: Experimental and Numerical Analyses. Procedia Engineering, 119, pp. 235-242, 2015.

[6] Lescovich, J.E., The Control of Water Hammer by Automatic Valve, American Water Works Association, 59(5), pp. 632-644, 1967.

[7] Ghidaoui, M.S., Zhao, M., McInnis, D.A. \& Axworthy, D.H., A Review of Water Hammer. Theory and Practice. Applied Mechanics Reviews, 58, pp. 49-76, 2005.

[8] Donghyuk, K. \& Kazuhiko, Y., Analytical Study of Cavitation Surge in a Hydraulic System. ASME J. of Fluids Eng, 136(10), 2014.

[9] Brunone, B., Karney, B., Mercarelli, M. \& Ferrante, M., Velocity Profiles and Unsteady Pipe Friction in Transient Flow. Journal of Water Resources Planning and Management, ASCE, 126(4), pp. 236-244, 2000. 
[10] Gale, J., Tiselj, I. \& Horvat, A., Two-fluid model of the WAHA code for simulations of water hammer transients. Multiphase Science and Technology, 20(3-4), pp. 291322, 2008.

[11] Brito, M., Sanches, P., Ferreira, M. \& Covas, D., PIV Characterization of Transient Flow in Pipe Coils. $16^{\text {th }}$ Conference on Water Distribution System Analysis, WDSA 2014, Italy, 89, pp. 1358-1365, 2014.

[12] Christopher, E., Cloud cavitation: observations, calculations and shock waves. Multiphase Science and Technology, 10(4), pp. 303-321, 1998.

[13] Al-Khomairi, A. \& Ead, S., Sizing of a plastic chamber with air-filled balls for water hammer control. Advances in Fluid Mechanics VIII Conference, (69), 2010. 